\title{
Colossal Magnetoresistance in Focus: Studies of Different CMR Materials by Mössbauer Spectroscopy
}

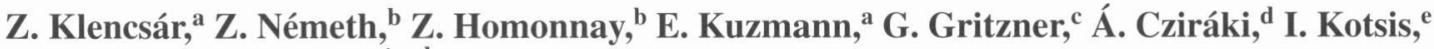 \\ M. Nagy, and A. Vértes*,a,b \\ ${ }^{a}$ Research Group for Nuclear Methods in Structural Chemistry, Hungarian Academy of Sciences, Roosevelt t. 9., \\ Budapest 1051, Hungary \\ ${ }^{\mathrm{b}}$ Department of Nuclear Chemistry, Eötvös Loránd University, Pázmány P. s. 1/a, Budapest 1117, Hungary \\ ${ }^{\mathrm{c}}$ Institut für Chemische Technologie Anorganischer Stoffe, Johannes Kepler Universität, A-4040 Linz, Austria \\ ${ }^{\mathrm{d} D e p a r t m e n t ~ o f ~ S o l i d ~ S t a t e ~ P h y s i c s, ~ E o ̈ t v o ̈ s ~ L o r a ́ n d ~ U n i v e r s i t y, ~ P O B ~ 32, ~} 1518$ Budapest, Hungary \\ ${ }^{\mathrm{e}}$ Department of Silicate- and Materials Engineering, University of Veszprém, Hungary
}

\section{Received: December 13, 2003}

The study of transition metal based materials displaying colossal magnetoresistance (CMR) is one of today's most exciting fields of research mainly due to the scientific challenge of finding the possibly common root (if that exists) of the CMR effect in the various materials. In this review we present novel results obtained by ${ }^{57} \mathrm{Fe}$ Mössbauer studies done on three different types of CMR materials, namely the cobalt based perovskites $\mathrm{La}_{0.8} \mathrm{Sr}_{0.2} \mathrm{Fe}_{x} \mathrm{Co}_{1-x} \mathrm{O}_{3-\mathrm{d}}$, the $\mathrm{Sr}_{2} \mathrm{FeMoO}_{6}$ double perovskite, and copper containing chalcogenide spinels $\left(\mathrm{Fe}_{1-x} \mathrm{Cu}_{x} \mathrm{Cr}_{2} \mathrm{~S}_{4}\right)$.

\section{Introduction}

Magnetoresistance (MR) is the change of the electrical resistivity due to an applied external magnetic field. It is usually expressed as $M R=[R(H)-R(0)] / R(0)$ where $R(0)$ and $R(H)$ denote the electrical resistivity measured without and with $H$ external magnetic field applied, respectively. In the case of negative magnetoresistance the value of $M R$ is restricted to the range of $-100 \%$ to $0 \%$. Although magnetoresistance was known long ago, the technological applicability of the MR effect was only available when giant negative magnetoresistance (GMR) was found in magnetic multilayers even at room temperature. These materials are used nowadays in the read-heads of several magnetic storage devices. The discovery of an even higher MR in manganese perovskites (called colossal magnetoresistance, CMR ${ }^{1}$ raised renewed interest in the transition metal based materials with anomalous MR properties.

In the present article we report the results of some recent investigations on members of three different classes of CMR materials: $\mathrm{La}_{0.8} \mathrm{Sr}_{0.2} \mathrm{Fe}_{x} \mathrm{Co}_{1-x} \mathrm{O}_{3-\mathrm{d}}$ perovskites, $\mathrm{Sr}_{2} \mathrm{FeMoO}_{6}$ double perovskite, and $\mathrm{Fe}_{1-x} \mathrm{Cu}_{x} \mathrm{Cr}_{2} \mathrm{~S}_{4}$ chalcogenide spinels.

The magnetoresistance properties of the investigated materials are demonstrated in Figure 1. The figure illustrates well the variety of magnetoresistance phenomena in materials with different structure. While the $\mathrm{Fe}_{x} \mathrm{Cu}_{1-x} \mathrm{Cr}_{2} \mathrm{~S}_{4}$ spinels show a CMR effect ${ }^{2}$ similar to that observed originally in the manganese perovskites, in the double perovskite system $\mathrm{Sr}_{2} \mathrm{FeMoO}_{6}, M R$ decreases near linearly with temperature, ${ }^{3}$ and the iron doped cobalt perovskites display huge negative $M R$ below $\sim 50 \mathrm{~K}$ as well as above $\sim 150 \mathrm{~K}^{4}$

Iron is thought to play a key role in the realization of magnetoresistance in each of the investigated compounds. Consequently, the study of the local state of iron as a function of temperature, sample composition, etc. may reveal the microscopic background of the magnetoresistance effect in these systems. As ${ }^{57} \mathrm{Fe}$ Mössbauer spectroscopy can reflect even

*Corresponding author. E-mail: vertesa@ludens.elte.hu. FAX: +36-1-209-06-02.
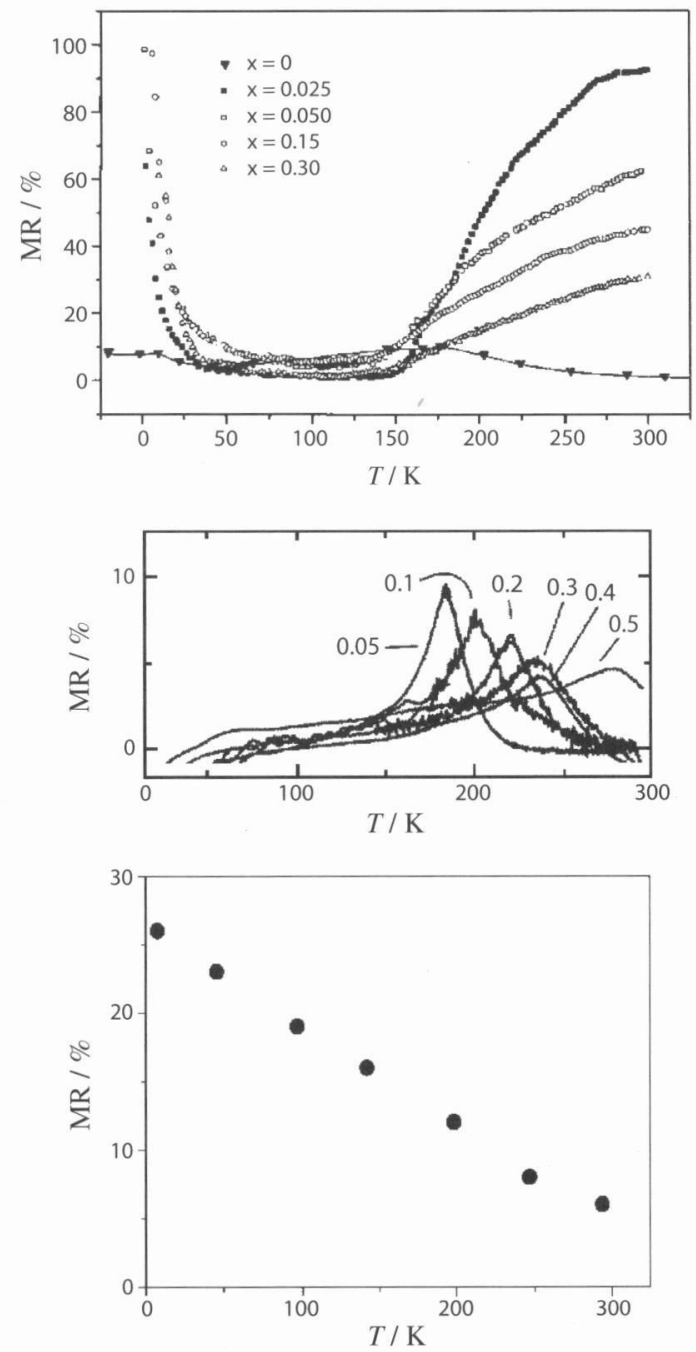

Figure 1. Magnetoresistance properties of $\mathrm{La}_{0.8} \mathrm{Sr}_{0.2} \mathrm{Fe}_{x} \mathrm{Co}_{1-x} \mathrm{O}_{3-\mathrm{d}}$ perovskites $^{4}$ (top, the magnetic field was $7.5 \mathrm{~T}$ for $x>0$ and $7 \mathrm{~T}$ for $x$ $=0$ ), $\mathrm{Fe}_{1-x} \mathrm{Cu}_{x} \mathrm{Cr}_{2} \mathrm{~S}_{4}$ chalcogenide spinels ${ }^{2}$ (in the middle, the numbers inside the picture correspond to the copper concentration, $x$, the applied magnetic field was $5 \mathrm{~T}$ ), and $\mathrm{Sr}_{2} \mathrm{FeMoO}_{6}$ double perovskite ${ }^{3}$ (bottom, measured in a magnetic field of $0.4 \mathrm{~T}$ ). 
minute changes in the local electronic, magnetic, and vibrational state of iron, it is an especially useful tool in the study of these materials.

\section{2. $\mathrm{La}_{0.8} \mathrm{Sr}_{0.2} \mathrm{Fe}_{x} \mathrm{Co}_{1-x} \mathrm{O}_{3-\mathrm{d}}$ Perovskites}

While in manganese perovskites the colossal magnetoresistance effect is observed only at temperatures in the neighborhood of the Curie temperature, iron doped $\mathrm{La}_{0.8} \mathrm{Sr}_{0.2} \mathrm{Fe}_{x} \mathrm{Co}_{1-x} \mathrm{O}_{3-\mathrm{d}}$ $(0.025<x<0.3)$ display negative magnetoresistance that increases monotonically with temperature in the temperature interval $150 \mathrm{~K} \leq T \leq 300 \mathrm{~K}$. Additionally, $\mathrm{La}_{0.8} \mathrm{Sr}_{0.2} \mathrm{Fe}_{x} \mathrm{Co}_{1-x} \mathrm{O}_{3-\mathrm{d}}$ also displays strong negative MR below $T \approx 50 \mathrm{~K} .{ }^{4}$ The negative MR observed above $T \approx 150 \mathrm{~K}$ is particularly interesting because, unlike in the case of manganites, in $\mathrm{La}_{0.8} \mathrm{Sr}_{0.2} \mathrm{Fe}_{x} \mathrm{Co}_{1-x} \mathrm{O}_{3-\mathrm{d}}$ the magnitude of MR increases continuously even in the paramagnetic phase. Namely, the Curie-temperature of the iron free end member $\mathrm{La}_{0.8} \mathrm{Sr}_{0.2} \mathrm{CoO}_{3-\mathrm{d}}$ is $T_{\mathrm{C}} \approx 180 \mathrm{~K},{ }^{5}$ and $T_{\mathrm{C}}$ decreases with the $x$ iron concentration. ${ }^{6}$

Above $T \approx 150 \mathrm{~K}$, the amplitude of negative magnetoresistance in $\mathrm{La}_{0.8} \mathrm{Sr}_{0.2} \mathrm{Fe}_{x} \mathrm{Co}_{1-x} \mathrm{O}_{3-\mathrm{d}}$ perovskites was found to decrease with increasing iron concentration in the range of 0.025 to 0.3. At the same time, the iron free $\mathrm{La}_{0.8} \mathrm{Sr}_{0.2} \mathrm{CoO}_{3-\mathrm{d}}$ perovskite displays only a modest magnetoresistance effect around its Curie-temperature. This suggests that iron plays a key role in the realization of the considerable negative magnetoresistance observed in $\mathrm{La}_{0.8} \mathrm{Sr}_{0.2} \mathrm{Fe}_{x} \mathrm{Co}_{1-x} \mathrm{O}_{3-\mathrm{d}}$ perovskites. ${ }^{4,7}$

One of the main questions regarding these perovskites is how already a low amount of iron substituted for Co manages to change dramatically the MR properties of the mother compound $\mathrm{La}_{0.8} \mathrm{Sr}_{0.2} \mathrm{CoO}_{3-\mathrm{d}}$. To collect information in this regard, we decided to take a closer look on the temperature dependence of the local state of iron in $\mathrm{La}_{0.8} \mathrm{Sr}_{0.2}{ }^{57} \mathrm{Fe}_{0.05} \mathrm{Co}_{0.95} \mathrm{O}_{3-\mathrm{d}}$. The local electronic, magnetic and vibrational state of iron can be advantageously studied by the help of ${ }^{57} \mathrm{Fe}$ transmission and ${ }^{57} \mathrm{Co}\left({ }^{57} \mathrm{Fe}\right.$ ) emission Mössbauer spectroscopy (in the followings referred to as TMS and EMS, respectively).

The $\mathrm{La}_{0.8} \mathrm{Sr}_{0.2}{ }^{57} \mathrm{Fe}_{0.05} \mathrm{Co}_{0.95} \mathrm{O}_{3-\mathrm{d}}$ sample was prepared by the following method. At first, $\mathrm{La}_{0.8} \mathrm{Sr}_{0.2} \mathrm{CoO}_{3}$ samples were fabricated via the citric acid-ethylene glycol method. The stoichiometric amounts of $\mathrm{La}\left(\mathrm{NO}_{3}\right)_{3} \cdot 6 \mathrm{H}_{2} \mathrm{O}, \mathrm{SrCO}_{3}$ and $\mathrm{Co}\left(\mathrm{NO}_{3}\right)_{2} \cdot 6 \mathrm{H}_{2} \mathrm{O}$ were dissolved in $50 \mathrm{~mL}$ of concentrated nitric acid. ${ }^{57} \mathrm{Fe}$ metal was dissolved in nitric acid and the respective aliquot was added to the nitric acid solution. The solution was diluted with $200 \mathrm{~mL}$ water. Thirty grams of citric acid and $8 \mathrm{~g}$ of ethylene glycol were added. The aqueous solution was evaporated until a brown gel was obtained. The gels were dried under vacuum at $125^{\circ} \mathrm{C}$. The residues were ground, first heated to $500^{\circ} \mathrm{C}$, kept this temperature for two hours and then heated to $800^{\circ} \mathrm{C}$. The heating rates were $5 \mathrm{~K} \mathrm{~min}^{-1}$. The samples were kept at $800^{\circ} \mathrm{C}$ for five hours. Upon ballistic cooling the samples were ground and compacted at $750 \mathrm{MPa}$ into discs of $10 \mathrm{~mm}$ diameter. The specimens were then sintered in air at $1200^{\circ} \mathrm{C}$ for 24 hours. Heating rates were $3 \mathrm{~K} \mathrm{~min}^{-1}$, cooling rates $10 \mathrm{~K} \mathrm{~min}^{-1}$.

${ }^{57} \mathrm{Fe}$ transmission Mössbauer spectroscopy measurements were carried out on powdered samples. The temperature dependent ${ }^{57} \mathrm{Fe}$ TMS measurements were performed in a temperature controlled flow-through type liquid nitrogen cryostat (Leybold) and an APD type liquid He cooled cryostat. During the measurements the temperature of the samples was kept constant with a precision of $\Delta T \approx \pm 0.5 \mathrm{~K}$. The $\gamma$-rays were provided by a ${ }^{57} \mathrm{Co}(\mathrm{Rh})$ source with $10^{9} \mathrm{~Bq}$ activity.

For the purpose of ${ }^{57} \mathrm{Co}\left({ }^{57} \mathrm{Fe}\right)$ emission Mössbauer measurements, the $\mathrm{La}_{0.8} \mathrm{Sr}_{0.2}{ }^{57} \mathrm{Fe}_{0.05} \mathrm{Co}_{0.95} \mathrm{O}_{3-\mathrm{d}}$ sample was doped by ${ }^{57} \mathrm{Co}$. Ethanolic solution of $100 \mathrm{MBq}$ carrier-free ${ }^{57} \mathrm{Co}$-nitrate was transferred onto the La-Sr-cobaltate pellet drop-by-drop, and after the evaporation of the alcohol, the pellet was treated for 3 hours in dry oxygen flow at $1000^{\circ} \mathrm{C}$ for a perfect isotopic exchange. XRD measurement confirmed that the perovskite structure and the composition of the original sample were not changed during the associated heat treatment. Two Mössbauer spectra using the conventional emission geometry ${ }^{8}$ were recorded at $4.2 \mathrm{~K}$ (in a helium bath cryostat) and at room temperature.

${ }^{57} \mathrm{Fe}$ isomer shift values are given relative to $\alpha$-iron at room temperature. Mössbauer spectra were analyzed with version 3.0 of the MossWinn program. ${ }^{9}$

${ }^{57} \mathrm{Fe}$ transmission Mössbauer spectra of $\mathrm{La}_{0.8} \mathrm{Sr}_{0.2}{ }^{57} \mathrm{Fe}_{0.05} \mathrm{Co}_{0.95} \mathrm{O}_{3-\mathrm{d}}$ at different temperatures are shown in Figure 2 . Above $T \approx 45$ $\mathrm{K}$ the spectrum consists of a quadrupole doublet with a small quadrupole splitting $(\Delta)$ of $\Delta \approx 0.2 \mathrm{~mm} \mathrm{~s}^{-1}$. The isomer shift ( $\delta$ ) of the doublet increases from $\delta \approx 0.33 \mathrm{~mm} \mathrm{~s}^{-1}$ at $T=290 \mathrm{~K}$ to $\delta \approx 0.4 \mathrm{~mm} \mathrm{~s}^{-1}$ at $T=80 \mathrm{~K}$. These $\delta$ and $\Delta$ values indicate that the electronic state of iron is high spin $\mathrm{Fe}^{3+}\left(\mathrm{t}_{2 \mathrm{~g}}{ }^{3} \mathrm{e}_{\mathrm{g}}{ }^{2}\right)$ in this compound, and in contrast to some assumptions (see, e.g., Reference 10) it does not support the existence of $\mathrm{Fe}^{4+}$ in this system. The Lorentzian curves of the quadrupole doublet are rather broad; their line width $(\Gamma)$ is around $\Gamma \approx 0.35 \mathrm{~mm} \mathrm{~s}^{-1}$ at $T=290 \mathrm{~K}$ and it increases with decreasing temperature.

In the spectrum taken at $T=45 \mathrm{~K}$ the quadrupole doublet is superimposed on a strongly broadened absorption curve (Figure 2). This latter broadened subspectrum originates from iron cations whose magnetic moment displays a slowed-down relaxation rate compared to the iron cations contributing to the paramagnetic spectrum component still observable in the Mössbauer spectrum. Namely, when the relaxation time of the magnetic moment of iron becomes comparable to the Larmor precession time $\left(\tau_{\mathrm{L}} \approx 10^{-7} \mathrm{~s}\right)$ of the ${ }^{57} \mathrm{Fe}$ nucleus, then the magnetic hyperfine interaction, although still being averaged out to some extent, becomes observable in the ${ }^{57} \mathrm{Fe}$ Mössbauer spectrum. A further slow-down of magnetic relaxation with decreasing temperature results in the appearance of a fulldeveloped sextet as clearly observed in the spectrum taken at $T$ $=10 \mathrm{~K}$.

The detailed temperature dependence of the $\delta, \Delta$, and $\Gamma^{57} \mathrm{Fe}$ Mössbauer parameters of $\mathrm{La}_{0.8} \mathrm{Sr}_{0.2}{ }^{57} \mathrm{Fe}_{0.05} \mathrm{Co}_{0.95} \mathrm{O}_{3-\mathrm{d}}$ are shown

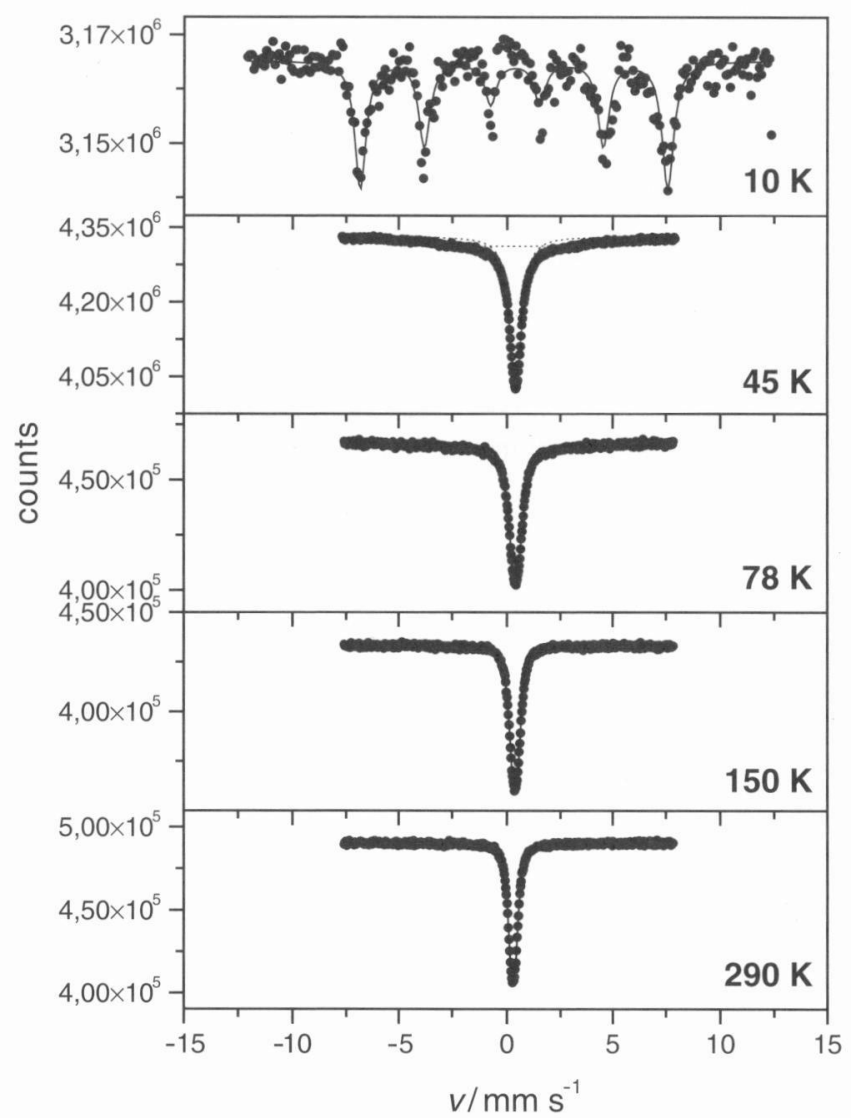

Figure 2. ${ }^{57} \mathrm{Fe}$ transmission Mössbauer spectra of $\mathrm{La}_{0.8} \mathrm{Sr}_{0.2}{ }^{57} \mathrm{Fe}_{0.05} \mathrm{Co}_{0.95} \mathrm{O}_{3-\mathrm{d}}$ at selected temperatures. 
in Figure 3.

The ${ }^{57} \mathrm{Fe}$ isomer shift decreases linearly with temperature from $78 \mathrm{~K}$ to $\sim 150 \mathrm{~K}$ and from $\sim 160 \mathrm{~K}$ to room temperature, but at $\sim 150 \mathrm{~K}$ the slope of the decline changes.

The gradient $\frac{d \delta(T)}{d T}$ is inversely proportional to the effective vibrating mass $\left(M_{\text {vibr }}\right)$ of the iron cations. ${ }^{11}$ The magnitude of $\frac{d \delta(T)}{d T}$ increases suddenly at $\sim 150 \mathrm{~K}$, which is equivalent to a sudden decrease in $M_{\text {vibr }}$ with increasing temperature. Such a decrease is to be expected when the vibrational motion of iron and that of the neighboring cations becomes less correlated due to a decrease in the force that made them move in a more correlated manner previously. Thus a sudden decrease in the strength of the chemical bonding or in the strength of the magnetic interaction between iron and its surroundings may well result in a sudden decrease of $M_{\text {vibr }}$. The ratio $M_{\text {vibr }}(T>150 \mathrm{~K}) / M_{\text {vibr }}(T<$ $150 \mathrm{~K}) \approx 2 / 3$ indicates that the vibrational state of iron changes considerably at $T \approx 150 \mathrm{~K}$ in $\mathrm{La}_{0.8} \mathrm{Sr}_{0.2}{ }^{57} \mathrm{Fe}_{0.05} \mathrm{Co}_{0.95} \mathrm{O}_{3-\mathrm{d}}$.

The Mössbauer line width of the quadrupole doublet starts to rise (with decreasing temperature) at around the same temperature $(T \approx 150 \mathrm{~K})$ where the effective vibrating mass changes suddenly (Figure 3 ). The evaluated ${ }^{57} \mathrm{Fe}$ quadrupole splitting (Figure 3) also increases with decreasing temperature in correlation with the line width.

The temperature $T \approx 150 \mathrm{~K}$ at the same time coincides with the ferromagnetic ordering temperature $\left(T_{\mathrm{C}}\right)$ of $\mathrm{La}_{0.8} \mathrm{Sr}_{0.2}{ }^{57} \mathrm{Fe}_{0.05} \mathrm{Co}_{0.95} \mathrm{O}_{3-\mathrm{d}}{ }^{6}$ Thus it is plausible to assume that the sudden decrease of $M_{\text {vibr }}$ at $T \approx 150 \mathrm{~K}$ is a consequence of the FM $\rightarrow$ PM transition of $\mathrm{La}_{0.8} \mathrm{Sr}_{0.2}{ }^{57} \mathrm{Fe}_{0.05} \mathrm{Co}_{0.95} \mathrm{O}_{3-\mathrm{d}}$. Similarly, the rather anomalous increase of $\Gamma$ and $\Delta$ Mössbauer parameters with decreasing temperature below $T \approx 150 \mathrm{~K}$ is likely to be of magnetic origin. The increase of the Mössbauer line width reflects that the relaxation time of the iron magnetic moment increases to around $10^{-8} \mathrm{~s}$ when the Co host matrix orders magnetically. Such an increased relaxation time is expected to occur when

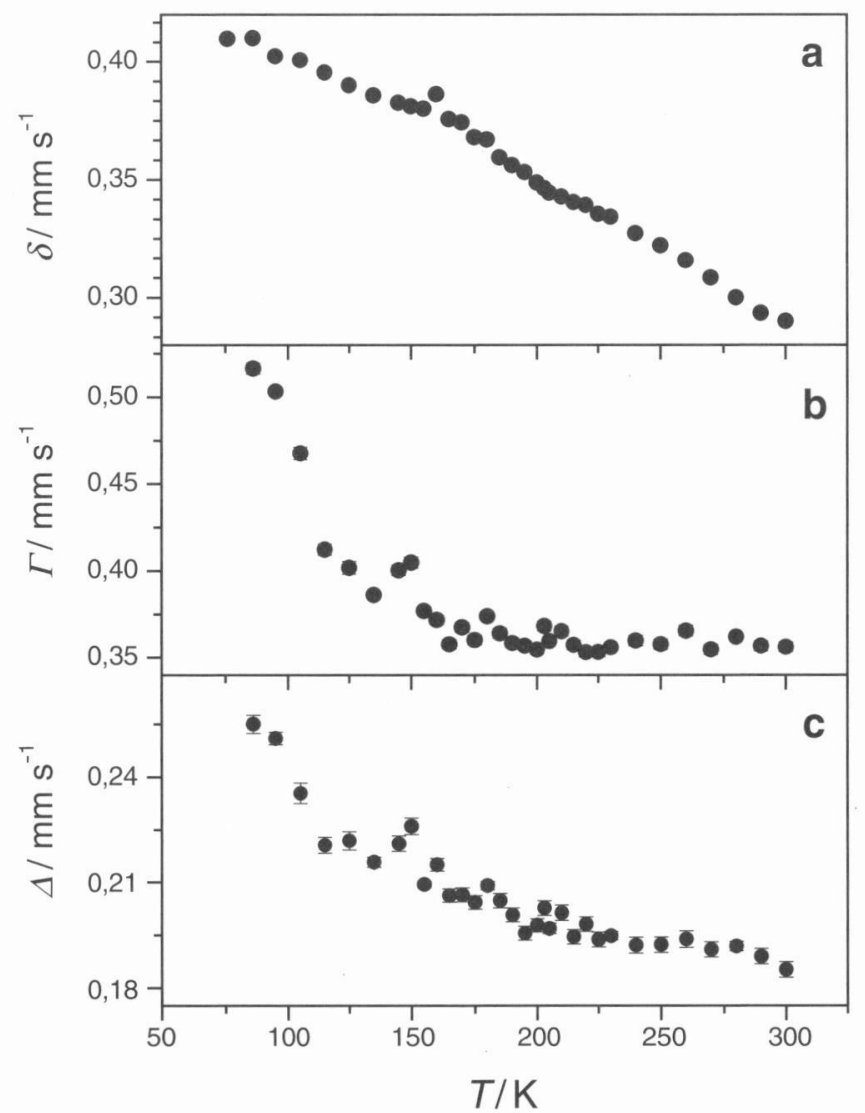

Figure 3. The temperature dependence of ${ }^{57} \mathrm{Fe}$ Mössbauer isomer shift $(\delta)$, line width $(\Gamma)$, and quadrupole splitting $(\Delta)$ of $\mathrm{La}_{0.8} \mathrm{Sr}_{0.2}{ }^{57} \mathrm{Fe}_{0.05} \mathrm{Co}_{0.95} \mathrm{O}_{3-\mathrm{d}}$. iron magnetic moments are relaxing not individually like in a paramagnet, but they are part of nanosized magnetic clusters as is the case, e.g., in superparamagnetic materials. When the relaxation time increases over the Larmor precession time of the ${ }^{57} \mathrm{Fe}$ nucleus, then a full-developed magnetic spectrum is observed as displayed in Figure 2. At this point one should note that the apparent increase in the $\Delta$ parameter with decreasing temperature (Figure 3 ) below $T \approx 150 \mathrm{~K}$ is not necessarily connected to a change in the quadrupole interaction, but it may also be the result of the slowing down of magnetic relaxation that appears in the spectrum as an apparent increase in the separation of the two broadened lines that we fit as a doublet.

Figure 4 shows the ${ }^{57} \mathrm{Co}\left({ }^{57} \mathrm{Fe}\right)$ EMS spectrum of $\mathrm{La}_{0.8} \mathrm{Sr}_{0.2}{ }^{57} \mathrm{Fe}_{0.05} \mathrm{Co}_{0.95} \mathrm{O}_{3-\mathrm{d}}$ at temperatures $4.2 \mathrm{~K}$ and $290 \mathrm{~K}$. The results obtained in this way are basically the same as obtained by the TMS technique (Figure 2). This shows that in this compound the electronic relaxation time of the nucleogenic iron is much shorter than the lifetime of the excited Mössbauer nuclear level of the ${ }^{57} \mathrm{Fe}$ nucleus $\left(\sim 10^{-7} \mathrm{~s}\right)$, and as a consequence the Mössbauer parameters observed via the EMS measurement also reflect the equilibrium chemical state of iron cations. In this case, however, as the nucleogenic iron is formed at the site of a Co cation, the values we obtain for the ${ }^{57} \mathrm{Fe}$ Mössbauer parameters represent the state of iron cations situated at $C o$ sites in $\mathrm{La}_{0.8} \mathrm{Sr}_{0.2}{ }^{57} \mathrm{Fe}_{0.05} \mathrm{Co}_{0.95} \mathrm{O}_{3-\mathrm{d}}$. The good agreement between the ${ }^{57} \mathrm{Fe}$ Mössbauer parameters obtained via TMS and EMS techniques shows that in $\mathrm{La}_{0.8} \mathrm{Sr}_{0.2}{ }^{57} \mathrm{Fe}_{0.05} \mathrm{Co}_{0.95} \mathrm{O}_{3-\mathrm{d}}$ the substituted $5 \mathrm{~mol} \%{ }^{57} \mathrm{Fe}$ does not form iron clusters, but it is distributed (probably near uniformly) in the Co host matrix. Thus, considering also the relatively low amount of ${ }^{57} \mathrm{Fe}$ present in the system, the magnetic state of iron has to be determined solely by Fe-Co magnetic exchange interactions.

The observation of magnetic relaxation in the ${ }^{57} \mathrm{Fe}$ Mössbauer spectra below the magnetic ordering temperature indicates that the magnetic moment of iron is strongly connected to and relaxes together with magnetically ordered nanosized Co clusters. This indicates that the magnetic exchange interaction between $\mathrm{Fe}$ and $\mathrm{Co}$ is strong in this system, and consequently when the material gets ordered magnetically at $T \approx 150 \mathrm{~K}$ iron magnetic moments get also ordered (or are already ordered) with respect to neighboring Co magnetic moments. As a consequence, the relaxation behavior we observe in the ${ }^{57} \mathrm{Fe}$ Mössbauer spectra of $\mathrm{La}_{0.8} \mathrm{Sr}_{0.2}{ }^{57} \mathrm{Fe}_{0.05} \mathrm{Co}_{0.95} \mathrm{O}_{3-\mathrm{d}}$ must correspond to the magnetic relaxation of nanosized Co clusters existing in this perovskite. This result further confirms the ide $\mathrm{a}^{12}$ that the existence of nanoscale magnetic clusters is a prerequisite of intrinsic negative magnetoresistivity.

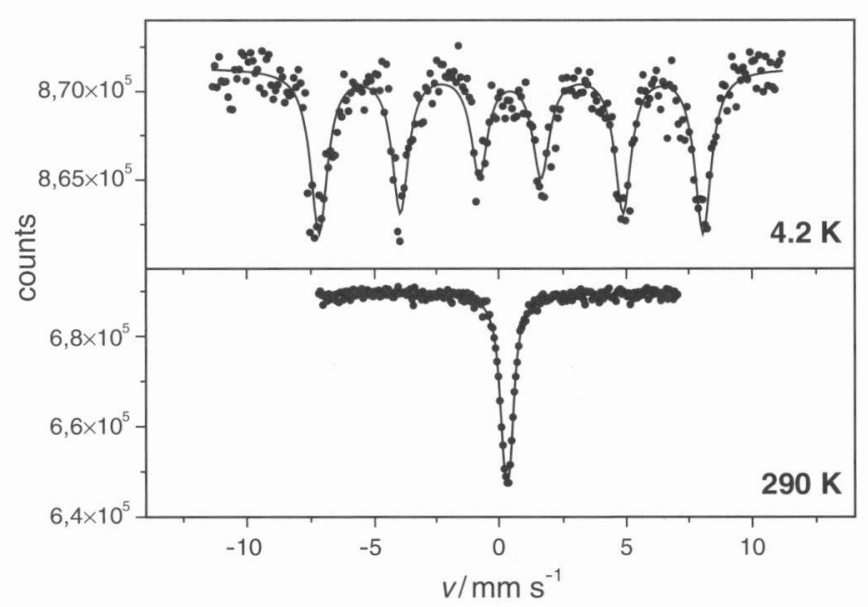

Figure 4. ${ }^{57} \mathrm{Co}\left({ }^{57} \mathrm{Fe}\right)$ emission Mössbauer spectra of $\mathrm{La}_{0.8} \mathrm{Sr}_{0.2}{ }^{57} \mathrm{Fe}_{0.05} \mathrm{Co}_{0.95} \mathrm{O}_{3-\mathrm{d}}$ at temperatures $4.2 \mathrm{~K}$ and $290 \mathrm{~K}$. 


\section{3. $\mathrm{Sr}_{2} \mathrm{FeMoO}_{6}$ : A Double Perovskite System}

The double perovskites $\mathrm{Sr}_{2} \mathrm{FeMoO}_{6}$ has been brought recently into the center of scientific interest because of their considerable magnetoresistance observed already in relatively low magnetic fields even at and above room temperature. ${ }^{13-19}$

The double perovskite $\mathrm{Sr}_{2} \mathrm{FeMoO}_{6}$ has been reported to have the cubic $\mathrm{ABO}_{3}$ structure that contains $\mathrm{Fe}$ and Mo cations ordered alternately at the $\mathrm{B}$ site. ${ }^{14}$

$\mathrm{Sr}_{2} \mathrm{FeMoO}_{6}$ has long been known as a conducting ferrimagnet with a relatively high magnetic transition temperature of $T_{\mathrm{c}} \approx 450 \mathrm{~K} .^{20}$ Recently, however, neutron diffraction measurements revealed zero magnetic moment on Mo cations, and consequently the ferrimagnetic structure of $\mathrm{Sr}_{2} \mathrm{FeMoO}_{6}$ was disputed. ${ }^{14}$ It was suggested, that while localized magnetic moment can be found only on ferromagnetically arranged $\mathrm{Fe}^{3+}$ cations, the $4 \mathrm{~d}^{1}$ electron of Mo is delocalized as well as spin polarized due to the involvement of $\mathrm{Fe}^{3+} \mathrm{t}_{2 \mathrm{~g}}$ levels in the conduction band, the latter being formed by the hybridization of $3 \mathrm{~d}(\mathrm{Fe})$ and $4 \mathrm{~d}(\mathrm{Mo})$ electronic states. ${ }^{14,} 16-18$

At the same time, in $\mathrm{Sr}_{2} \mathrm{FeMoO}_{6}$ saturation magnetic moments of $3.0 \mu_{\mathrm{B}},{ }^{13} 3.6 \mu_{\mathrm{B}},{ }^{3} 3.18 \mu_{\mathrm{B}},{ }^{20}$ and $3.08 \mu_{\mathrm{B}}{ }^{21}$ were observed at low temperatures on the basis of magnetization measurements. These values are below the range from $4 \mu_{\mathrm{B}}$ to $5 \mu_{\mathrm{B}}$ expected for $\mathrm{Fe}^{+(3-\delta)}$, where $\delta \leq 1$ denotes the contribution of the delocalized electron to the Fe minority spin $t_{2 g}$ level. The decreased value of saturation magnetic moment has been attributed to a deviation from the perfectly ordered structure by the replacement of a certain amount of Mo by $\mathrm{Fe}$ and vice versa. Indeed, it was shown that iron substituting Mo aligns antiferromagnetically to neighboring iron cations in $\mathrm{Sr}_{2} \mathrm{FeMoO}_{6}{ }^{22}$ Recently it was suggested that this kind of antisite defects might be responsible for low field magnetoresistance observed in polycrystalline $\mathrm{Sr}_{2} \mathrm{FeMoO}_{6}{ }^{23,24}$

In order to gain insight into the effects of cation disorder on the local electronic structure, in this article we studied a double perovskite $\mathrm{Sr}_{2} \mathrm{FeMoO}_{6}$ that contains a considerable amount of misplaced cations.

The studied $\mathrm{Sr}_{2} \mathrm{FeMoO}_{6}$ sample was prepared in the following way. Stoichiometric mixture of $\mathrm{SrCO}_{3}, \mathrm{Fe}_{2} \mathrm{O}_{3}$, and $\mathrm{MoO}_{3}$ was homogenized and pressed into pellet under a pressure of $100 \mathrm{MPa}$. The pellet was calcined in air at $900^{\circ} \mathrm{C}$ for 4 hours. The precursor obtained in this way, consisting of $\mathrm{SrMoO}_{4}$ and $\mathrm{SrFeO}_{3}$, was grinded and pressed again into a pellet. This procedure was followed by a heat treatment at $900^{\circ} \mathrm{C}$ for 2 hours under nitrogen atmosphere containing 5

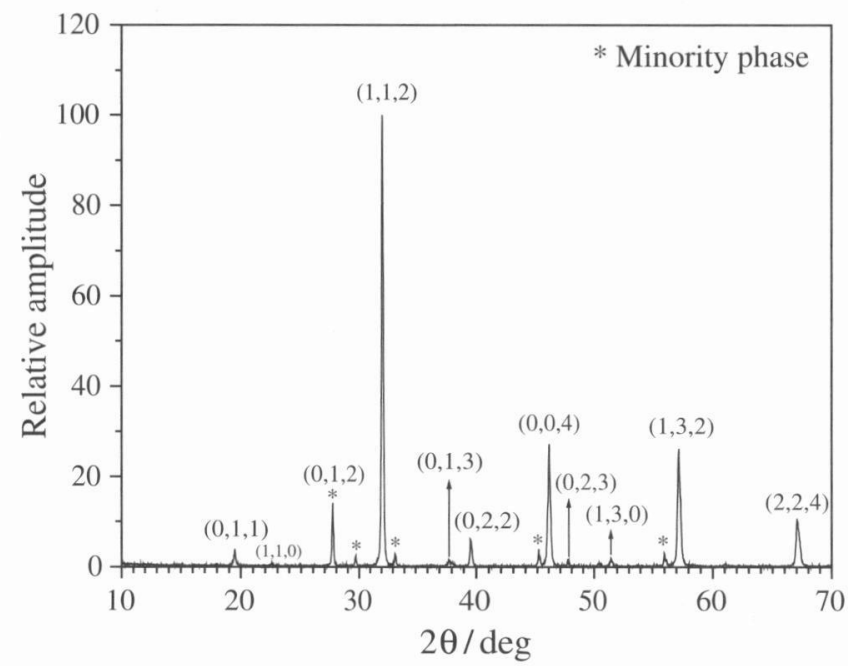

Figure 5. X-ray diffractogram of $\mathrm{Sr}_{2} \mathrm{FeMoO}_{6}$ powder measured with $\mathrm{Cu} \mathrm{K} \mathrm{K}_{\alpha}(\lambda=0.154184 \mathrm{~nm})$ radiation at room temperature. The $(h \mathrm{kl})$ indexing of the peaks is shown for the $I 4 / \mathrm{m}$ tetragonal structure. The peaks belonging to the minority phase are marked by $*$ sign. The strongest line of the minority phase coincides with the (012) line of the main phase.
$(V / V) \% \mathrm{H}_{2}$. The heat treatment was repeated once after regrinding and repressing the sample.

Figure 5 shows the X-ray diffractogram of the investigated $\mathrm{Sr}_{2} \mathrm{FeMoO}_{6}$ sample. The diffractogram can be decomposed into two components. The crystal structure of the main component can be identified as a double perovskite with a tetragonal $I 4 / \mathrm{m}$ space group and a lattice parameter of $a=$ $0.5586 \mathrm{~nm}$ and $c=0.7888 \mathrm{~nm}$. This result is in agreement with the earlier neutron diffraction investigations ${ }^{19}$ indicating that below $420^{\circ} \mathrm{C}$ the $14 / \mathrm{m}$ tetragonal and above this temperature the cubic $F m 3 m$ structure is stable.

The Bragg peaks not belonging to the double perovskite structure originate from a simple tetragonal minority phase with $I 4 / a$ space group and with cell parameters of $a=0.53943$ $\mathrm{nm}$ and $c=1.20436 \mathrm{~nm}$. The volume fraction of this simple tetragonal phase, calculated on the basis of the ratio of integrated Bragg line intensities, was estimated to be around $6 \%$. The cell parameters of this minority phase are very close to that of the precursor material $\mathrm{SrMoO}_{4}$ (I4/a tetragonal, $a=$ $0.53944 \mathrm{~nm}, c=1.2020 \mathrm{~nm}$ ).

Figure 6 shows the ${ }^{57} \mathrm{Fe}$ Mössbauer spectrum of $\mathrm{Sr}_{2} \mathrm{FeMoO}_{6}$ measured at $T=4.2 \mathrm{~K}$. The spectrum can be decomposed into four different magnetically split subspectra reflecting magnetically ordered iron cations with different electronic configurations on their $3 \mathrm{~d}$ level. In the followings, these subspectra will be referred to as S1 (61\%), S2 (13\%), S3 (15\%), and S4 $(11 \%)$. The ${ }^{57} \mathrm{Fe}$ isomer shift and hyperfine magnetic field $(B)$ parameters belonging to the observed subspectra are visualized in Figure 7 together with the corresponding electronic configu-

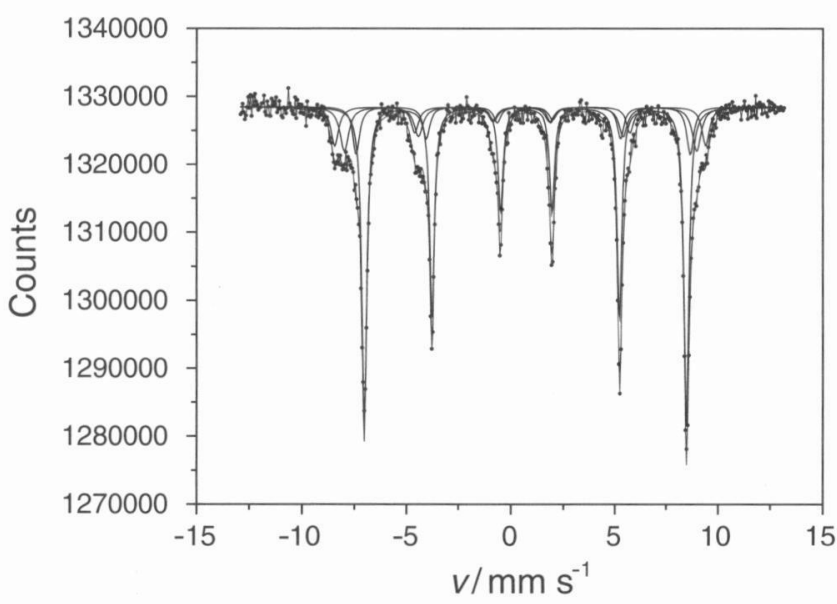

Figure 6. ${ }^{57} \mathrm{Fe}$ Mössbauer spectrum of $\mathrm{Sr}_{2} \mathrm{FeMoO}_{6}$ at $T=4.2 \mathrm{~K}$, and its decomposition into four magnetically split subspectra.

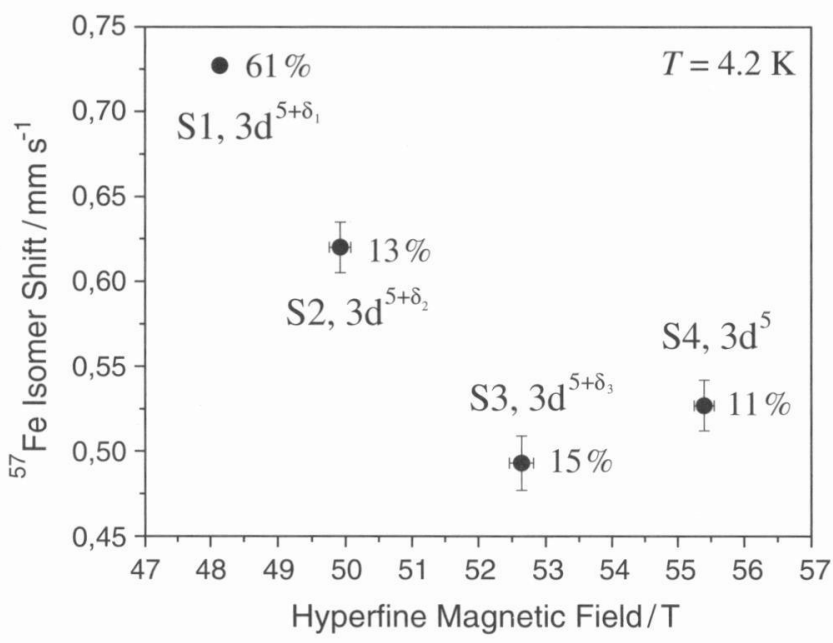

Figure 7. ${ }^{57} \mathrm{Fe}$ isomer shift and hyperfine magnetic field Mössbauer parameters obtained for the four magnetic subcomponents observed in the ${ }^{57} \mathrm{Fe}$ Mössbauer spectrum of $\mathrm{Sr}_{2} \mathrm{FeMoO}_{6}$ at $T=4.2 \mathrm{~K}$. The suggested electronic configurations of the corresponding iron cations are indicated next to the data points. It is assumed that $\delta_{3}<\delta_{2}<\delta_{1}$. 
ration of the iron cations. The main sextet $\mathrm{S} 1$ can be attributed to the ideal, perfectly ordered regions of the double perovskite. Its Mössbauer parameters agree well with those reported in Reference 19 for $\mathrm{Sr}_{2} \mathrm{FeMoO}_{6}$. While the corresponding isomer shift value is relatively high, the hyperfine magnetic field is relatively low compared to the values expected for high spin $\mathrm{Fe}^{3+}$ at $T=4.2 \mathrm{~K}\left(\delta \approx 0.5 \mathrm{~mm} \mathrm{~s}^{-1}, B \approx 55 \mathrm{~T}\right)$. This points to a considerable electron density on the minority spin $\mathrm{t}_{2 \mathrm{~g}}$ level of iron, which is in agreement with a high degree of hybridization between $3 \mathrm{~d}(\mathrm{Fe})$ and $4 \mathrm{~d}(\mathrm{Mo})$ electronic levels. Furthermore, the intermediate value of isomer shift and hyperfine magnetic field Mössbauer parameters, i.e. between values that would be representative for $\mathrm{Fe}^{3+}$ and $\mathrm{Fe}^{2+}$, indicates that the $\delta_{1}$ minority spin electron density at the $3 \mathrm{~d}^{5+\delta_{1}}$ level of iron (Figure 7) arises from delocalized electrons. The S2 magnetic component in the ${ }^{57} \mathrm{Fe}$ Mössbauer spectrum was also detected earlier in $\mathrm{Sr}_{2} \mathrm{FeMoO}_{6}{ }^{19}$ This component displays a decreased isomer shift and an increased hyperfine magnetic field compared to the case of the perfectly ordered structure represented by S1 (Figure 7). This corresponds to a decreased electron density $\left(\delta_{2}\right)$ at the minority spin $3 \mathrm{~d}^{5+\delta_{2}}$ level of iron. The decreased minority spin electron density can be interpreted as a reduced degree of delocalization of the $4 \mathrm{~d}^{1}$ electron of Mo.

In contrast with earlier ${ }^{57} \mathrm{Fe}$ Mössbauer studies done on $\mathrm{Sr}_{2} \mathrm{FeMoO}_{6}$ with moderate levels of cation disorder, in the Mössbauer spectrum of our $\mathrm{Sr}_{2} \mathrm{FeMoO}_{6}$ we observe two more subspectra, S3 and S4, whose hyperfine magnetic field is higher and whose ${ }^{57} \mathrm{Fe}$ isomer shift is lower than the corresponding values representing S1 and S2. Thus, S3 and S4 can be attributed to an electronic state of iron where the degree of delocalization of the minority spin electron is further reduced compared to the case of S1 and S2. Actually, the ${ }^{57} \mathrm{Fe}$ Mössbauer parameters of the component S4 (Figure 7) already refer to a fully localized state of high spin $\mathrm{Fe}^{3+}$ with the $3 \mathrm{~d}^{5}$ electronic configuration. Although the isomer shift of the species S3 equals that of S4 within the experimental uncertainty, its decreased hyperfine magnetic field already refers to the existence of moderate minority spin electron density on the $3 \mathrm{~d}^{5+\delta_{3}}$ level of the corresponding iron cations (Figure 7). The less pronounced difference between the isomer shift of S3 and S4 can be explained by assuming that beside the $3 \mathrm{~d}(\mathrm{Fe})$ and $4 \mathrm{~d}(\mathrm{Mo})$ electronic states the $4 \mathrm{~s}(\mathrm{Fe})$ electronic state of iron is also involved in some extent in the hybridization of electronic levels forming the conduction band.

The relatively high extent of cation disorder expected to be present in our sample is thought to be responsible for the appearance of the two additional sextets, S3 and S4. This means that cation disorder results in a decreased delocalization of the $4 \mathrm{~d}^{1}$ electron of Mo. Misplaced cations are expected to form barriers to delocalized electrons. For example, an antisite iron is expected to repel itinerant electrons of spin polarized nature because of its antiferromagnetic alignment relative to neighboring iron cations. Thus, cation disorder leads to electrically insulating domains in the otherwise half metallic double perovskite. The degree of electronic insulation at the same time is expected to depend on the size of the insulating domains. While the electrons may enter into the domain boundaries and may also pass through thin insulating domains, they are completely excluded from the inside of bulkier domains. Accordingly, in the presence of domains with considerable volume fraction of cation disorder, iron cations belonging to different levels of minority spin electron density are expected to exist in the double perovskite. This explains the appearance of the magnetic subcomponents S2, S3, and S4 in the ${ }^{57} \mathrm{Fe}$ Mössbauer spectrum of $\mathrm{Sr}_{2} \mathrm{FeMoO}_{6}$. Namely, while $\mathrm{S} 2$ can be attributed to moderate disorder levels (e.g. isolated antisite defects), S3 and S4 may arise from iron cations located in the inside of bulkier insulating domains.

\section{4. $\mathrm{Fe}_{1-x} \mathrm{Cu}_{x} \mathrm{Cr}_{2} \mathrm{~S}_{4}$ Type Spinels}

Apart from perovskites, recently chalcogenide spinels were also found showing remarkable CMR properties. ${ }^{2,25-27}$ Although Mössbauer studies of some iron containing chalcogenides were already performed several decades ago (see, e.g., Reference 28), we present some new ${ }^{57} \mathrm{Fe}$ Mössbauer measurements in order to gain a deeper insight into the structure of $\mathrm{Fe}_{1-x} \mathrm{Cu}_{x} \mathrm{Cr}_{2} \mathrm{~S}_{4}$ type chalcogenides.

The $\mathrm{Fe}_{1-x} \mathrm{Cu}_{x} \mathrm{Cr}_{2} \mathrm{~S}_{4}(x=0,0.25,0.5$, and 0.75$)$ specimens were prepared by solid state reactions. The stoichiometrically mixed samples sealed in an evacuated quarz tube were fired for $12 \mathrm{~h}$ at $850^{\circ} \mathrm{C}$, and then they were ground and pressed into pellets. Sample purity was checked by X-ray diffraction and by scanning electron microscopy in combination with energy dispersive X-ray fluorescence spectroscopy. ${ }^{29}{ }^{57} \mathrm{Fe}$ Mössbauer spectroscopy measurements were carried out on the $\mathrm{Fe}_{1-x} \mathrm{Cu}_{x} \mathrm{Cr}_{2} \mathrm{~S}_{4}$ samples in transmission geometry with a conventional constant acceleration type spectrometer. ${ }^{57} \mathrm{Fe}$ isomer shifts are given relative to $\alpha$-iron at room temperature.

The temperature dependence of the ${ }^{57} \mathrm{Fe}$ Mössbauer parameters characteristic for iron at the tetrahedral site in the sample $\mathrm{FeCr}_{2} \mathrm{~S}_{4}(x=0)$ was published earlier. ${ }^{30,31}$ The Curie temperature $\left(T_{\mathrm{c}}\right)$ was found to be about $170 \mathrm{~K}$ and the magnetic field was $20 \mathrm{~T}$ in this sample at $76 \mathrm{~K}$. The isomer shift $(\delta)$ was 0.72 $\mathrm{mm} \mathrm{s}^{-1}$ at $76 \mathrm{~K}$ and it decreased to $0.6 \mathrm{~mm} \mathrm{~s}^{-1}$ when the temperature was increased to room temperature. These parameters confirm the oxidation level of iron(II). ${ }^{30}$

Figure $8 \mathrm{a}$ and $\mathrm{b}$ show the ${ }^{57} \mathrm{Fe}$ Mössbauer spectra of the samples $\mathrm{Fe}_{1-x} \mathrm{Cu}_{x} \mathrm{Cr}_{2} \mathrm{~S}_{4}$ (for $x=0,0.25,0.5$, and 0.75 ) recorded at room temperature. As clearly reflected by the ${ }^{57} \mathrm{Fe}$

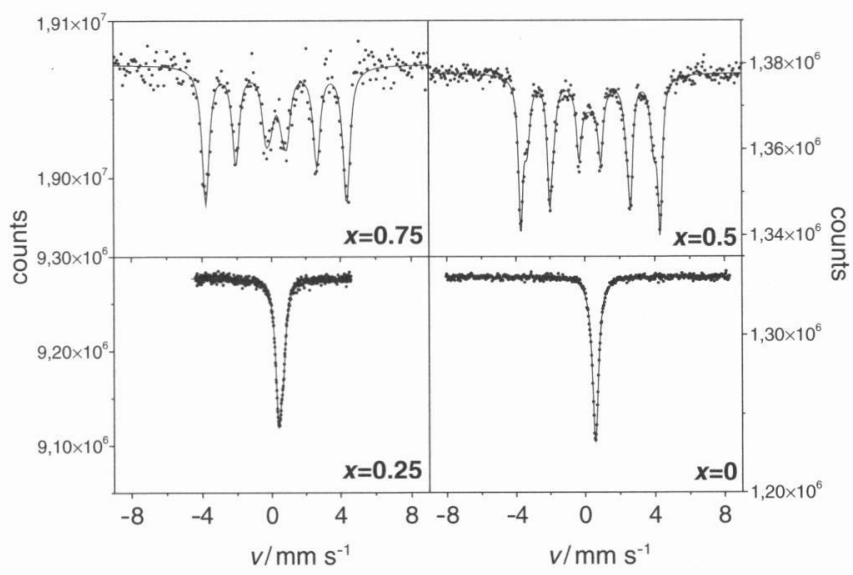

Figure 8a. ${ }^{57} \mathrm{Fe}$ Mössbauer spectra of $\mathrm{Fe}_{1-x} \mathrm{Cu}_{x} \mathrm{Cr}_{2} \mathrm{~S}_{4}(x=0,0.25,0.5$, and 0.75 ) at room temperature (only the envelope of the fitting curves are shown).

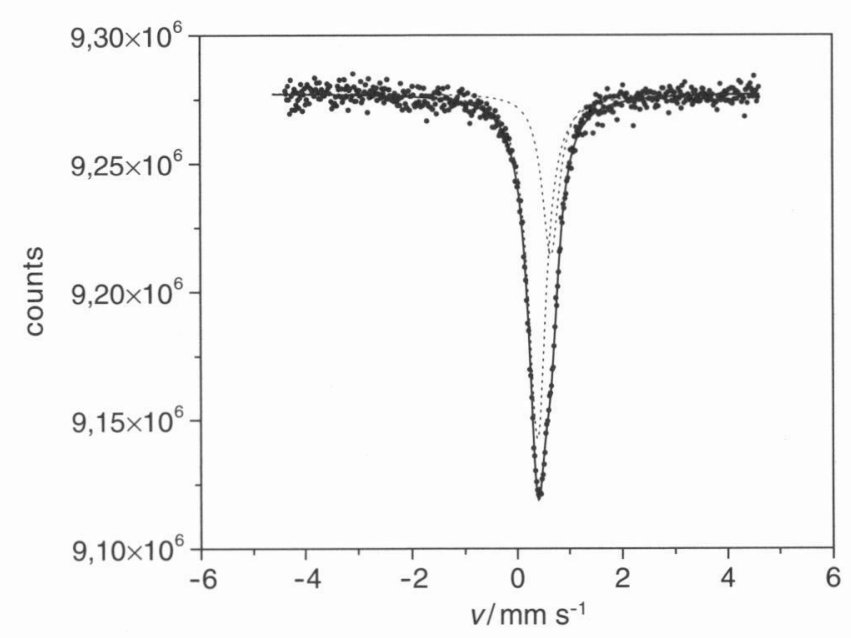

Figure 8b. ${ }^{57} \mathrm{Fe}$ Mössbauer spectrum of $\mathrm{Fe}_{0.75} \mathrm{Cu}_{0.25} \mathrm{Cr}_{2} \mathrm{~S}_{4}$ at room temperature showing the decomposition of the absorption curve into two singlets belonging to paramagnetic $\mathrm{Fe}^{3+}$ and $\mathrm{Fe}^{2+}$. 
Mössbauer spectrum shown in Figure 8b, already a substitution of $25 \%$ of iron with $\mathrm{Cu}$ results in considerable differences in the oxidation state of iron in these compounds. While in $\mathrm{FeCr}_{2} \mathrm{~S}_{4}$ all iron cations display the same $\left(\mathrm{Fe}^{2+}\right)$ oxidation state, the ${ }^{57} \mathrm{Fe}$ Mössbauer spectrum of $\mathrm{Fe}_{0.75} \mathrm{Cu}_{0.25} \mathrm{Cr}_{2} \mathrm{~S}_{4}$ consists of two clearly distinguishable subspectra each revealing a different oxidation state of iron in the chalcogenide. The singlet with Mössbauer isomer shift $\delta=0.66(1) \mathrm{mm} \mathrm{s}^{-1}$ can be assigned to $\mathrm{Fe}^{2+}$ state that has been reported in $\mathrm{FeCr}_{2} \mathrm{~S}_{4} \cdot{ }^{30}$ The second singlet with isomer shift $\delta=0.40(1) \mathrm{mm} \mathrm{s}^{-1}$, however, undoubtedly refers to the existence of $\mathrm{Fe}^{3+}$ cations in the $\mathrm{Fe}_{0.75} \mathrm{Cu}_{0.25} \mathrm{Cr}_{2} \mathrm{~S}_{4}$ sample. Considering the requirement of charge neutrality, and assuming that the concentration of sulfur vacancies is negligible compared to the concentration of $\mathrm{Cu}$, it follows that at least part of the $\mathrm{Cu}$ being present in the system must be in the $\mathrm{Cu}^{+}$state. If all the copper in the sample would be in the $\mathrm{Cu}^{+}$state, then one would expect the relative amount of $\mathrm{Fe}^{2+}$ and $\mathrm{Fe}^{3+}$ to be $\mathrm{Fe}^{2+}: \mathrm{Fe}^{3+}=2: 1$. The room temperature ${ }^{57} \mathrm{Fe}$ Mössbauer spectrum of $\mathrm{Fe}_{0.75} \mathrm{Cu}_{0.25} \mathrm{Cr}_{2} \mathrm{~S}_{4}$ is, however, not in agreement with this expectation (Figure 8b). Namely, by comparing the peak areas belonging to $\mathrm{Fe}^{2+}$ and $\mathrm{Fe}^{3+}$ one observes a ratio of $\mathrm{Fe}^{2+}: \mathrm{Fe}^{3+} \approx 1: 2.2$. One should consider, however, that the ratio of Mössbauer peak areas reflects faithfully the relative occurrence of the corresponding iron species only if the recoilless fraction (the probability of the Mössbauer effect, also called the Mössbauer-Lamb factor) is the same for the two species. As the recoilless fraction should have a tendency to approach $100 \%$ (from below) with decreasing temperature for all species, a Mössbauer measurement carried out at a lower temperature should result in a Mössbauer spectrum in which the area ratio of the peaks reflects the relative occurrence of the corresponding iron species more faithfully than it does in the case of the measurement done at room temperature (Figure 8a). For this reason we also carried out a ${ }^{57} \mathrm{Fe}$ Mössbauer measurement of $\mathrm{Fe}_{0.75} \mathrm{Cu}_{0.25} \mathrm{Cr}_{2} \mathrm{~S}_{4}$ at $T=77 \mathrm{~K}$, which resulted in the Mössbauer spectrum shown in Figure 9. The Mössbauer spectrum at $T=77 \mathrm{~K}$ can be decomposed into three different components. The component belonging to $\mathrm{Fe}^{2+}$ is now a magnetically split sextet $\left(\delta=0.67(2) \mathrm{mm} \mathrm{s}^{-1}, B=\right.$
22.9(2) $\mathrm{T}$ ) showing that at $T=77 \mathrm{~K} \mathrm{Fe}^{2+}$ cations are already ordered magnetically in agreement with results obtained earlier for $\mathrm{FeCr}_{2} \mathrm{~S}_{4} \cdot{ }^{30,31}$ At the same time we observe two different subspectra with parameters representative for $\mathrm{Fe}^{3+}$. One of them is a magnetically split sextet $\left(\delta=0.52(1) \mathrm{mm} \mathrm{s}^{-1}, B=\right.$ 33.1(1) $\mathrm{T}$ ) showing that there are also $\mathrm{Fe}^{3+}$ cations magnetically ordered at $T=77 \mathrm{~K}$, whereas the other is a quadrupole doublet $\left(\delta=0.55(2) \mathrm{mm} \mathrm{s}^{-1}, \Delta=1.19(3) \mathrm{mm} \mathrm{s}^{-1}\right.$ ) referring to $\mathrm{Fe}^{3+}$ cations in the paramagnetic state. The relative area fraction of the latter component is $\sim 9 \%$. The nearly equal isomer shift of the two different $\mathrm{Fe}^{3+}$ components suggests that the corresponding cations may be situated in the same crystallographic position in $\mathrm{Fe}_{0.75} \mathrm{Cu}_{0.25} \mathrm{Cr}_{2} \mathrm{~S}_{4}$, but the iron cations belonging to the doublet are probably separated from the magnetically ordered regions (e.g. by sulfur vacancies) and consequently they display paramagnetic behavior at $T=77 \mathrm{~K}$. At the same time it is also not entirely excluded that the paramagnetic $\mathrm{Fe}^{3+}$ subspectrum at $T=77 \mathrm{~K}$ originates from some $\mathrm{FeS}_{x}$ impurities in the sample.

By analyzing the area ratio of subspectra belonging to $\mathrm{Fe}^{2+}$ and $\mathrm{Fe}^{3+}$ cations in the Mössbauer spectrum taken at $T=77 \mathrm{~K}$ one observes $\mathrm{Fe}^{2+}: \mathrm{Fe}^{3+} \approx 3: 2$ which ratio is closer to the expected ratio $2: 1$ than that observed at room temperature (1: 2.2). The significant difference between the apparent $\mathrm{Fe}^{2+}$ : $\mathrm{Fe}^{3+}$ ratios observed at $T=290 \mathrm{~K}$ and at $T=77 \mathrm{~K}$ indicates that in $\mathrm{Fe}_{0.75} \mathrm{Cu}_{0.25} \mathrm{Cr}_{2} \mathrm{~S}_{4}$ at room temperature the Mössbauer-Lamb factor belonging to $\mathrm{Fe}^{3+}$ is at least three times greater than that belonging to $\mathrm{Fe}^{2+}$. This result shows that by replacing iron with copper in $\mathrm{Fe}_{1-x} \mathrm{Cu}_{x} \mathrm{Cr}_{2} \mathrm{~S}_{4}$ it is not only the oxidation state of iron that changes, but simultaneously with the transition $\mathrm{Fe}^{2+} \rightarrow \mathrm{Fe}^{3+}$ the local vibrational state of iron cations is altered considerably, too.

In contrast with $\mathrm{Fe}_{0.75} \mathrm{Cu}_{0.25} \mathrm{Cr}_{2} \mathrm{~S}_{4}$, the compounds $\mathrm{Fe}_{0.5} \mathrm{Cu}_{0.5} \mathrm{Cr}_{2} \mathrm{~S}_{4}$ and $\mathrm{Fe}_{0.25} \mathrm{Cu}_{0.75} \mathrm{Cr}_{2} \mathrm{~S}_{4}$ are magnetically ordered already at room temperature as revealed by the corresponding ${ }^{57} \mathrm{Fe}$ Mössbauer spectra in Figure 8.

The Mössbauer spectrum of $\mathrm{Fe}_{0.5} \mathrm{Cu}_{0.5} \mathrm{Cr}_{2} \mathrm{~S}_{4}$ can be decomposed into a magnetically split sextet (with parameters $\delta=$ $0.31(1) \mathrm{mm} \mathrm{s}^{-1}, B=24.5(1) \mathrm{T}$ ) and a quadrupole doublet (with

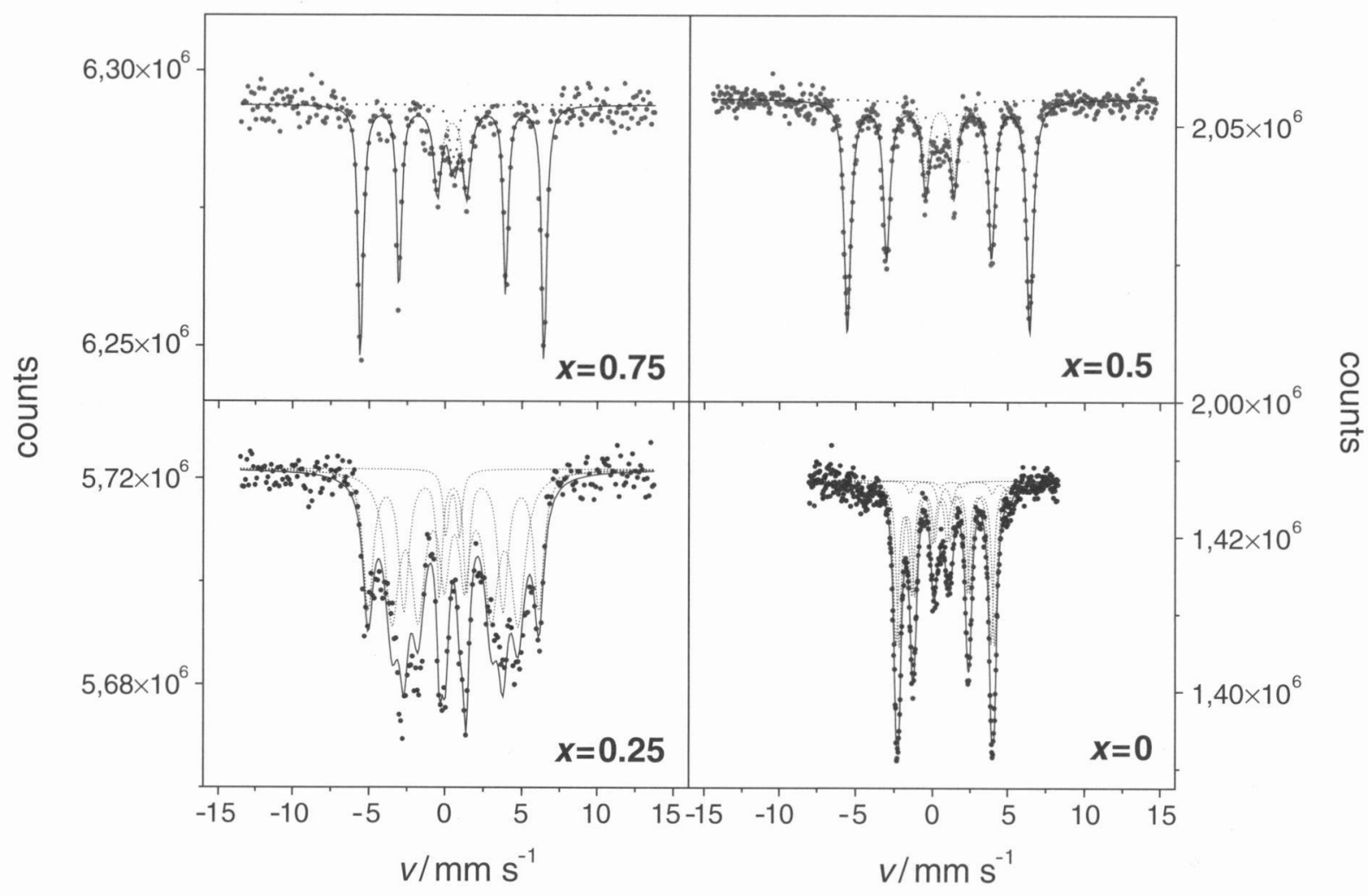

Figure 9. ${ }^{57} \mathrm{Fe}$ Mössbauer spectra of $\mathrm{Fe}_{1-x} \mathrm{Cu}_{x} \mathrm{Cr}_{2} \mathrm{~S}_{4}(x=0,0.25,0.5$, and 0.75$)$ at $T \approx 77 \mathrm{~K}$. 
TABLE 1: ${ }^{57} \mathrm{Fe}$ Mössbauer Parameters of $\mathrm{Fe}_{1-x} \mathrm{Cu}_{x} \mathrm{Cr}_{2} \mathrm{~S}_{4}(x=0,0.25,0.5$, and 0.75$)$ Chalcogenide Spinels

\begin{tabular}{|c|c|c|c|c|c|c|c|c|}
\hline \multirow{2}{*}{$\begin{array}{l}\text { Sample } \\
T / \mathrm{K}\end{array}$} & \multicolumn{2}{|c|}{$\mathrm{FeCr}_{2} \mathrm{~S}_{4}$} & \multicolumn{2}{|c|}{$\mathrm{Fe}_{0.75} \mathrm{Cu}_{0.25} \mathrm{Cr}_{2} \mathrm{~S}_{4}$} & \multicolumn{2}{|c|}{$\mathrm{Fe}_{0.5} \mathrm{Cu}_{0.5} \mathrm{Cr}_{2} \mathrm{~S}_{4}$} & \multicolumn{2}{|c|}{$\mathrm{Fe}_{0.25} \mathrm{Cu}_{0.75} \mathrm{Cr}_{2} \mathrm{~S}_{4}$} \\
\hline & $75 \mathrm{~K}$ & $290 \mathrm{~K}$ & $78 \mathrm{~K}$ & $290 \mathrm{~K}$ & $76 \mathrm{~K}$ & $290 \mathrm{~K}$ & $77 \mathrm{~K}$ & $290 \mathrm{~K}$ \\
\hline $\mathrm{Fe}^{2+} / \%$ & 100 & 100 & 59 & 31 & - & - & - & - \\
\hline$\delta / \mathrm{mm} \mathrm{s}^{-1}$ & 0.71 & 0.59 & 0.65 & 0.66 & - & - & - & - \\
\hline$B / \mathrm{T}$ & 20.0 & - & 22.6 & - & - & - & - & - \\
\hline $\mathrm{Fe}^{3+}(\mathbf{M}) / \%$ & - & - & 32 & - & 88 & 90 & 94 & 82 \\
\hline$\delta / \mathrm{mm} \mathrm{s}^{-1}$ & - & - & 0.51 & - & 0.43 & 0.31 & 0.42 & 0.30 \\
\hline$B / \mathrm{T}$ & - & - & 33.0 & - & 37.2 & 24.5 & 37.3 & 25.3 \\
\hline $\mathbf{F e}^{3+}(\mathbf{P M}) / \%$ & - & - & 9 & 69 & 12 & 10 & 6 & 18 \\
\hline$\delta / \mathrm{mm} \mathrm{s}^{-1}$ & - & - & 0.55 & 0.40 & 0.45 & 0.3 & 0.50 & 0.3 \\
\hline$\Delta / \mathrm{mm} \mathrm{s}^{-1}$ & - & - & $(1.2)$ & - & $(0.5)$ & $(1.0)$ & $(0.29)$ & $(0.9)$ \\
\hline
\end{tabular}

' $\mathrm{Fe}^{3+}(\mathrm{M})$ ' and ' $\mathrm{Fe}^{3+}(\mathrm{PM})$ ' denote magnetically ordered $\mathrm{Fe}^{3+}$ and $\mathrm{Fe}^{3+}$ in a paramagnetic state, respectively. Quadrupole splitting $(\Delta)$ values given in parentheses are uncertain because of the strong overlap of the absorption lines. Isomer shift $(\delta)$ and magnetic field $(B)$ Mössbauer parameters concerning $\mathrm{Fe}^{2+}$ in $\mathrm{FeCr}_{2} \mathrm{~S}_{4}$ at $T=75 \mathrm{~K}$ are average values, see Reference 30 for details.

parameters $\delta=0.31(3) \mathrm{mm} \mathrm{s}^{-1}, \Delta=0.9(1) \mathrm{mm} \mathrm{s}^{-1}$ ).

The relative area fraction of the doublet is $\sim 10 \%$. While at room temperature the two peaks of the doublet overlap with the inner two lines of the sextet, at $T \approx 76 \mathrm{~K}$ the existence of the doublet becomes more obvious (Figure 9). The origin of this doublet is likely to be the same as that found in the case of $\mathrm{Fe}_{0.75} \mathrm{Cu}_{0.25} \mathrm{Cr}_{2} \mathrm{~S}_{4}$ at $T=77 \mathrm{~K}$, namely $\mathrm{Fe}^{3+}$ in the neighborhood of a sulfur vacancy. This assignment is supported by the ${ }^{57} \mathrm{Fe}$ Mössbauer spectrum of $\mathrm{Fe}_{0.25} \mathrm{Cu}_{0.75} \mathrm{Cr}_{2} \mathrm{~S}_{4}$ at $T=290 \mathrm{~K}$ (Figure 8) which also contains a doublet with the same isomer shift and quadrupole splitting parameters, but the relative area fraction of this doublet is $18 \%$ which is a considerably increased value compared to the case of $\mathrm{Fe}_{0.5} \mathrm{Cu}_{0.5} \mathrm{Cr}_{2} \mathrm{~S}_{4}$. This increase can be understood again considering the requirement of macroscopic charge neutrality. Namely, the isomer shift of the main magnetic component in the ${ }^{57} \mathrm{Fe}$ Mössbauer spectra of $\mathrm{Fe}_{0.5} \mathrm{Cu}_{0.5} \mathrm{Cr}_{2} \mathrm{~S}_{4}$ and $\mathrm{Fe}_{0.25} \mathrm{Cu}_{0.75} \mathrm{Cr}_{2} \mathrm{~S}_{4}$ undoubtedly refers to $\mathrm{Fe}^{3+}$, which further supports that copper is present mainly in the $\mathrm{Cu}^{+}$ state in this system. It follows that without any sulfur vacancies in $\mathrm{Fe}_{0.5} \mathrm{Cu}_{0.5} \mathrm{Cr}_{2} \mathrm{~S}_{4}$ the capability of the iron subsystem to compensate for the presence of $\mathrm{Cu}^{+}$cations by the $\mathrm{Fe}^{2+} \rightarrow \mathrm{Fe}^{3+}$ transition (in order to maintain charge neutrality) is already fully exhausted. Therefore, if we replace more iron with $\mathrm{Cu}^{+}$ in the system, the missing positive charge has to be compensated by the appearance of sulfur vacancies (i.e. missing negative charges). And, assuming that the relative area fraction of the observed doublet component is really proportional to the number of sulfur vacancies, this is exactly what we observe in the ${ }^{57} \mathrm{Fe}$ Mössbauer spectra. (It should be noted here, that our reasoning remains valid even if a certain amount of copper is in the $\mathrm{Cu}^{2+}$ state in $\mathrm{Fe}_{1-x} \mathrm{Cu}_{x} \mathrm{Cr}_{2} \mathrm{~S}_{4}$ with $x \geq 0.5$.)

Although the ${ }^{57} \mathrm{Fe}$ isomer shift $\delta \approx 0.3 \mathrm{~mm} \mathrm{~s}^{-1}$ found for the chalcogenides with $x \geq 0.5$ clearly refers to $\mathrm{Fe}^{3+}$, the hyperfine magnetic field reflected by the main magnetic component in the ${ }^{57} \mathrm{Fe}$ Mössbauer spectrum of $\mathrm{Fe}_{0.5} \mathrm{Cu}_{0.5} \mathrm{Cr}_{2} \mathrm{~S}_{4}$ and $\mathrm{Fe}_{0.25} \mathrm{Cu}_{0.75} \mathrm{Cr}_{2} \mathrm{~S}_{4}$ (Table 1) is much lower than the typical magnetic fields in the high spin iron(III) compounds (45-55 T at $76 \mathrm{~K}$ ). This contradiction between the measured isomer shift and magnetic field values can be resolved if we take into account that there is a covalent bond between sulphur and iron and suppose that the electronic structure of iron in this sample is: $3 \mathrm{~d}^{5+x} 4 \mathrm{~s}^{y}$ with $x>0, y>0$.

\section{Conclusions}

Iron is thought to play a decisive role in determining the magnetic state and the MR properties of the studied perovskite $\left(\mathrm{La}_{0.8} \mathrm{Sr}_{0.2}{ }^{57} \mathrm{Fe}_{0.05} \mathrm{Co}_{0.95} \mathrm{O}_{3-\mathrm{d}}\right)$, double perovskite $\left(\mathrm{Sr}_{2} \mathrm{FeMoO}_{6}\right)$, and chalcogenide spinel $\left(\mathrm{Fe}_{1-x} \mathrm{Cu}_{x} \mathrm{Cr}_{2} \mathrm{~S}_{4}\right)$ systems. ${ }^{57} \mathrm{Fe}$ Mössbauer spectroscopy provided us with detailed information on the local vibrational, electronic and magnetic state of iron in the studied compounds, which enabled us to draw novel conclusions concerning the magnetic, electronic or defect structure of these systems. The further detailed exploration of the temperature dependence of the local state of iron in these compounds is promising because it may reveal correlations between the macroscopic MR properties and the local electronic and/or magnetic state of iron, which hopefully will bring us closer to the understanding of the possible microscopic backgrounds of the CMR effect in general.

Acknowledgements. This work was supported by the Hungarian Science Foundation OTKA (F 034837, T 034839, T02474, T 043687, T 043565) and by the Austrian Hungarian Action Foundation. Z. Klencsár acknowledges the support from the Hungarian Bolyai János research grant. The authors are thankful to Imre Vincze (KFKI, Budapest) for making available his facilities to record the Mössbauer spectrum of $\mathrm{Sr}_{2} \mathrm{FeMoO}_{6}$ at $T=4.2 \mathrm{~K}$, and also to $\mathrm{G}$. Molnar and A. Bousseksou (Laboratoire de Chimie de Coordination, CNRS, France) for the $T=10 \mathrm{~K}$ Mössbauer spectrum of $\mathrm{La}_{0.8} \mathrm{Sr}_{0.2}{ }^{57} \mathrm{Fe}_{0.05} \mathrm{Co}_{0.95} \mathrm{O}_{3-\mathrm{d}}$.

\section{References}

(1) S. Jin, T. H. Tiefel, M. McCormack, R. A. Fastnacht, R. Ramesh, and L. H. Chen, Science 264, 413 (1994).

(2) V. Fritsch, J. Deisenhofer, R. Fichtl, J. Hemberger, H.-A. Krug von Nidda, M. Mücksch, M. Nicklas, D. Samusi, J. D. Thompson, R. Tidecks, V. Tsurkan, and A. Loidl, Phys. Rev. B67, 144419 (2003).

(3) T.H. Kim, M. Uehara, S-W. Cheong, and S. Lee, Appl. Phys. Lett. 74, 1737 (1999).

(4) A. Barman, M. Ghosh, S. Biswas, S. K. De, and S. Chatterjee, Appl. Phys. Lett. 71, 3150 (1997).

(5) V. Golovanov, L. Mihály, and A. R. Moodenbaugh, Phys. Rev. B53, 8207 (1996).

(6) Z. Németh, Z. Klencsár, E. Kuzmann, Z. Homonnay, A. Vértes, B. Lackner, K. Kellner, G. Gritzner, J. Hakl, S. Mészáros, K. Vad, G. Molnár, and A. Bousseksou, to be published.

(7) Á. Cziráki, I. Gerőcs, M. Köteles, A. Gábris, L. Pogány, I. Bakonyi, Z. Klencsár, A. Vértes, S.K. De, A. Barman, M. Ghosh, S. Biswas, S. Chatterjee, B. Arnold, H. D. Bauer, K. Wetzig, C. Ulhaq-Bouillet, and V. Pierron-Bohnes, Eur. Phys. J. B21, 521 (2001).

(8) A. Vértes, S. Nagy, and Z. Klencsár, Handbook of Nuclear 
Chemistry (Kluwer Academic Publishers, Amsterdam, 2003).

(9)Z. Klencsár, E. Kuzmann, and A. Vértes, J. Radioanal. Nucl. Chem. 210, 105 (1996).

(10) L. W. Tai, M. M. Nasrallah, H. U. Anderson, D. M. Sparlin, and S. R. Sehlin, Solid State Ionics 76, 259 (1995).

(11) R. H. Herber, Chemical Mössbauer Spectroscopy (Plenum Press, New York, 1984).

(12) A. Nath, Z. Klencsár, E. Kuzmann, Z. Homonnay, A. Vértes, A. Simopoulos, E. Devlin, G. Kallias, A. P. Ramirez, and R. J. Cava, Phys. Rev. B66, 212401 (2002).

(13) K.-I. Kobayashi, T. Kimura, H. Sawada, K. Terakura, and Y. Tokura, Nature 395, 677 (1998).

(14) B. Garcia-Landa, C. Ritter, M. R. Ibarra, J. Blasco, P. A. Algarabel, R. Mahendiran, and J. Garcia, Solid State Comm. 110, 435 (1999).

(15) T. Manako, M. Izumi, Y. Konishi, K. Kobayashi, M. Kawasaki, and Y. Tokura, Appl. Phys. Lett. 74, 2215 (1999).

(16)Z. Fang, K. Terakura, and J. Kanamori, Phys. Rev. B63, 180407 (2001).

(17) J. Kanamori, Trans. Magn. Soc. Jpn. 1, 1 (2001).

(18) J. Kanamori and K. Terakura, J. Phys. Soc. Jpn. 70, 1433 (2001).

(19) O. Chmaissem, R. Kruk, B. Dabrowski, D. E. Brown, X. Xiong, S. Kolesnik, J. D. Jorgensen, and C. W. Kimball, Phys. Rev. B62, 14197 (2000).
(20) T. Nakagawa, J. Phys. Soc. Jpn. 24, 806 (1968).

(21) M. Itoh, I. Ohta, and Y. Inaguma, Mater. Sci. Eng. B41, 55 (1996).

(22) J. Linden, T. Yamamoto, M. Karppinen, H. Yamauchi, and T. Pietari, Appl. Phys. Lett. 76, 2925 (2000).

(23) T. Saha-Dasgupta and D. D. Sarma, Phys. Rev. B64, 064408 (2001).

(24) M. García-Hernández, J. L. Martínez, M. J. MartínezLope, M. T. Casais, and J. A. Alonso, Phys. Rev. Lett. 86, 2443 (2001).

(25) K. Ando, Y. Nishihara, T. Okuda, and T. Tsushima, J. Appl. Phys. 50(3), 1917 (1979).

(26) A. P. Ramirez, R. J. Cava, and J. Krajewski, Nature 386, 156 (1997).

(27)Z. Yang, S. Tan, Z. Chen, and Y. Zhang, Phys. Rev. B62, 13872 (2000).

(28) G. R. Hoy and K. P. Singh, Phys. Rev. 172, 514 (1968)

(29) M. Kühberger, Z. Klencsár, E. Kuzmann, Z. Homonnay, Z. Németh, G. Gritzner, and A. Vértes, to be published.

(30)Z. Klencsár, E. Kuzmann, Z. Homonnay, A. Vértes, A. Simopoulos, E. Devlin, and G. Kallias, J. Phys. Chem. Solids 64, 325 (2003).

(31)Z. Klencsár, E. Kuzmann, Z. Homonnay, A. Vértes, A. Simopoulos, E. Devlin, and G. Kallias, Hyperfine Interact. 144/145, 261 (2002). 